\title{
Traute Meyer, Paul Bridgen and Barbara Riedmüller (2007). Private Pensions versus Social Inclusion? Non-State Provision for Citizens at Risk in Europe. Cheltenham: Edward Elgar, 260 pp. ISBN 9781847203533 (available as e-book)
}

REVIEWED BY LARS HARRYSSON*

Research projects may be reported in different ways. This particular research group has chosen an audience of initiated scholars and policy makers. Thus, it is neither surprising nor questionable to hold this hard cover US\$ 130 volume in my hand with its cover illustration promoting a feeling of the Lord's sharing and enlightened palm balancing an air floating euro cent coin. I do not get the idea. Perhaps there is none.

Why this opening of my review of Meyer, Bridgen and Riedmüller's very interesting research project report? Well, I feel a troublesome conflict in the way the research results are chosen to be presented and the objective of the research and the positioning of those subjects' at risk it is said to represent. At first glance it really feels as if it is empty words providing a worry for those in needs, or presumably in need in the future, when these risk groups' experiences and ways of thinking are not represented in the research, which I believe is a necessary condition to understand what the meaning of a pension regime is.

* Lars Harrysson, School of Social Work, Lund University, Sweden. 
International Journal of Ageing and Later Life

So, while this volume is concerned with the re-distributive consequences of pension reforms enacted in Europe over the past decade to manage the effects of a graying society and based on projected socio-economic biographies, it does not provide life biographies based on narratives. That means leaving actual life experiences and personal pension planning and thoughts sidelined. Without such stories it is not possible to sketch real life pension regimes, but projected ones. The question then is who is controlling this projection. For whom are we producing these results, and for whom do they make a difference?

To be honest, I do not know. The choice of a publisher well known for high-quality economics volumes priced so that most cannot afford to buy them points in a direction of academic inclusion or status rather than a wish to enlighten those at risk. However, I may of course be wrong; it would not be the first time, and those actually in need of enlightenment are researchers, insurance managers, politicians and others. Or, in other words, it is aimed at those people who may have the power to make a difference, to change the world, in the authors' perspective. That is a topdown view on how things change, and I believe it makes the primary objective of the volume, which I will come back to shortly, problematic. I believe that important research, such as what is presented in this volume, should be accessible to a wider audience. Particularly students and other young people who are to fill the spots after our generation in universities, insurance companies and politics.... The book is available as e-book.

\section{The Overall Objective}

This volume has a "do good" perspective. It is concerned with worrying social consequences. In accepting that non-public ways of providing income support in old age have increased and that increasing government initiative are not to be expected, two major knowledge gaps have been identified and are addressed in the volume. Firstly a question of how financially sustainable the appearing private-public mixes are, and secondly in what ways these mixes provide security against exclusionary processes within retired groups. Using the editors' words I understand the over arching objective with the book as to: "explore to what extent widespread confidence that multi-pillar arrangements pose no major problems for levels of social exclusion is justified." (p. 5). 
The project is a simulation study based on a common set of biographies tested in six case nations; the UK, the Netherlands, Switzerland, which are referred to as private pension veterans, and Germany, Poland and Italy, referred to as newcomers. In each case the biographies have been simulated through the existing pension system. By comparing the simulation results in pension income to the national poverty, thresholds interpretations have been made to which degree these income levels can be seen as socially inclusive or not. The research group have been very good at keeping to the research design and thus provided comparability between the six nations. In combination with thorough descriptions of the national pension systems this volume holds more than isolated country reviews. This is a clear strength.

It is not an easy book to read, or review, and requires some prior knowledge about pension development, social policy issues and, if the results are to be discussed and questioned, statistical and econometric understanding. For those interested in the assumptions backing the arguments in the book, the construction of the biographies and limitations in the covering of pension systems are closely discussed and described. Particularly Appendices 1.1 and 1.2 are informative, but in each chapter additional national characteristics are added.

Private pensions are commonly viewed as closely connected to individual pension insurance, but that insurance is a way of collectively sharing risks is often forgotten. However, the result from this study clarifies that where private pensions form a compulsory collective system and the government provides a fairly generous basic system, the private character of a supplementary system does not necessarily mean noninclusive consequences for those at most risk. However, in most respects, seen as a provider of enough income for subsistence in old age, and here seen as inclusionary, the path of private solutions presents a risky alternative. Social inclusion is thus based on the notion that there is a common overarching way of sharing responsibilities in society, pensions no exception, and a notion I feel inclined to agree with. However, while this is a social inclusionary process, most rhetoric covering the change towards private-public mixes in pensions move free choice and personal responsibility to the forefront and in doing so promoting a clearly social exclusionary process. I miss a clear discussion on the process character of 
International Journal of Ageing and Later Life

inclusion and exclusion processes in the pension development. There is an indication in the final words of the volume opens for the historical and institutional character of the consequences of an implemented system of pension provision in a certain setting, or in other words a spill of path dependency. What I would have liked to see is a thorough discussion on how the methods used are able to fetch this kind of processes.

Finally, this is a book I think you should read if you are interested in pension development. It is a comprehensive study and in several ways it presents new paths and methods. However, watch out for and critically scrutinize the authors' way of treating stigma, compulsion, the time for private alternatives to form at government retrenchment, and pension regimes. 